\title{
Effects of Lateral Trunk Support on Scoliotic Spinal Alignment in Persons With Spinal Cord Injury: A Radiographic Study
}

\author{
Hui-Fen Mao, MS, OTR, Sheau-Ling Huang, MS, OTR, Tung-Wu Lu, DPhil, Yen-Sheng Lin, MS, \\ Hon-Man Liu, MD, Yen-Ho Wang, MD, Ting-Ming Wang, MD
}

ABSTRACT. Mao H-F, Huang S-L, Lu T-W, Lin Y-S, Liu H-M, Wang Y-H, Wang T-M. Effects of lateral trunk support on scoliotic spinal alignment in persons with spinal cord injury: a radiographic study. Arch Phys Med Rehabil 2006;87:764-71.

Objective: To develop a radiographic method for measuring the spinal alignment of a person in a seated position and with which to investigate the effects of lateral trunk supports (LTS) in special seating on the frontal and sagittal spinal alignment in persons with spinal cord injury (SCI).

Design: Before-after trial.

Setting: University-based research laboratory.

Participants: Ten men and 7 women who had SCI with scoliosis (age, 35.4 $\pm 9.4 \mathrm{y}$; injury level, C5-T11) voluntarily participated.

Intervention: An adjustable seating system with LTS.

Main Outcome Measures: Radiographs of the spine in the anteroposterior (AP) and lateral directions were taken while sitting on an adjustable seating system without and with LTS. The Cobb angles and scoliotic indices based on the AP radiographic images and the angles of the thoracic and lumbar spine based on lateral were calculated. The relative change in angle (RCA) with LTS in terms of the percentage reduction of the Cobb angles was also obtained.

Results: The Cobb angles and scoliotic indices while sitting with LTS were significantly smaller than those without, the mean difference of Cobb angles \pm standard error (SE) being $9.12^{\circ} \pm 1.64^{\circ}(P<.001)$ and those for the scoliotic indices being $.09 \pm .04 \quad(P=.027)$. The mean RCA \pm SE was $26.16 \% \pm 4.23 \%$. The RCA correlated weakly with the original Cobb angles $(r=-.347, P=.172)$. The LTS caused a significant reduction in the lumbar angles $(P<.001)$, but no significant effects on the thoracic angles were found.

Conclusions: The radiographic findings demonstrate improved scoliotic spinal alignment in the frontal plane and reduced lumbar angles in the sagittal plane in persons with SCI when seated in a special seat and using LTS.

Key Words: Orthotic devices; Radiography; Rehabilitation; Scoliosis; Spinal cord injuries.

From the School of Occupational Therapy (Mao, Huang), Institute of Biomedical Engineering (Lu, Lin), Departments of Radiology (Liu) and Physical Medicine and Rehabilitation (Wang Y-H), National Taiwan University, Taipei, Taiwan; and Department of Orthopaedics, National Taiwan University Hospital, Taipei, Taiwan (Wang T-M).

Supported by the National Science Council of Taiwan (grant no. NSC 91-2314B-002-393).

No commercial party having a direct financial interest in the results of the research supporting this article has or will confer a benefit upon the authors or upon any organization with which the authors are associated.

Correspondence to Tung-Wu Lu, DPhil, Institute of Biomedical Engineering, National Taiwan University, No. 1, Sec. 1, Jen-Ai Rd, Taipei 100, Taiwan, e-mail: twlu@ntu.edu.tw. Reprints are not available from the author.

0003-9993/06/8706-10727\$32.00/0

doi:10.1016/j.apmr.2006.02.029
(C) 2006 by the American Congress of Rehabilitation Medicine and the American Academy of Physical Medicine and Rehabilitation

$\mathbf{S}$ COLIOSIS, A CONDITION CHARACTERIZED by lateral curvature of the spine with rotation of the vertebrae and deformity in the sagittal plane, ${ }^{1-3}$ is often observed in persons with spinal cord injury (SCI) who have poor trunk control when using a wheelchair seating system. ${ }^{4-9}$ These spinal deformities can lead to back pain, pressure ulcers, and respiratory problems, affecting activities of daily living. ${ }^{7-11}$ The degree of the spinal curvature may increase over time. Clinical observations suggest that the greater the magnitude of the curvature, the greater the health and functional difficulties that are associated with it. ${ }^{12-14}$ The prevention of the progression of the spinal deformity remains a crucial issue in the management of persons with SCI.

Both surgical and nonsurgical treatment methods have been suggested for the management of the progression of the spinal deformity. ${ }^{1}$ Surgical correction of scoliotic deformity is usually suggested if the Cobb angle is greater than $40^{\circ} .{ }^{10}$ Although the effects of surgical correction have been shown in patients with cerebral palsy (CP) and adolescent subjects with idiopathic scoliosis, ${ }^{15,16}$ to date no studies have been conducted for the SCI population. The surgical intervention may provide good spinal curve correction, but the procedure may not be justified for routine cases when considering the risks of significant complications for these patients. ${ }^{15,17}$ For Cobb angles less than $40^{\circ}$, nonsurgical methods, such as the use of spinal braces and special seating, can serve as a viable alternative. ${ }^{10}$ These methods have focused mainly on the orthotic management of the scoliosis. ${ }^{1,18,19}$ Spinal braces have been reported to control scoliosis curve progression effectively for adolescents with idiopathic scoliosis, ${ }^{1,18,19}$ but the users often felt that the braces impacted negatively on their body image and felt uncomfortable and encumbered, especially when performing daily activities. $^{20}$ On the other hand, special wheelchair seating systems have been a more acceptable method in the management of spinal postural deformities, and may be helpful in the control of the progression of spinal deformities. ${ }^{8,21,22}$

Special seating has been widely used in clinical practice to improve the sitting posture of persons with SCI who have a low level of sitting ability and are unable to maintain their own sitting posture. There are many types of special seating with different components prescribed for different needs. ${ }^{8,21,22}$ For SCI persons with scoliosis, lateral trunk support (LTS) is among the basic components in seating prescriptions. ${ }^{22}$ Generally, LTS is applied at 3 positions on the trunk providing a so-called 3-point force system. ${ }^{23}$ Proper use of LTS may enable a better alignment and stabilization of the upper body in the frontal plane and potentially help prevent further spinal deformity. However, no study has quantified the influence of LTS in 
Table 1: Demographic Data of the Subjects

\begin{tabular}{lc}
\hline \multicolumn{1}{c}{ Demographic Data } & Value \\
\hline Subjects $(\mathrm{n})$ & 17 \\
Mean age $($ range) $(\mathrm{y})$ & $35.4(18.3-51.7)$ \\
Men/women $(\mathrm{n})$ & $10 / 7$ \\
Mean body weight $\pm \mathrm{SE}(\mathrm{kg})$ & $58.0 \pm 2.7$ \\
Mean body height $\pm \mathrm{SE}(\mathrm{cm})$ & $161.9 \pm 2.8$ \\
Time from onset (range) $(\mathrm{y})$ & $17.6(2.9-35.0)$ \\
\hline
\end{tabular}

Abbreviation: SE, standard error.

a special seating system on the spinal alignment in subjects with SCI.

Although LTS provides the trunk with supports in the frontal plane, and is presumably helpful for the reduction of the flexible scoliotic deformity of the spine, many persons with SCI in special seating with LTS subjectively described that they were able to sit more upright. Because the scoliotic deformity of the spine is 3 -dimensional in nature, ${ }^{24,25}$ correction of the spinal curve in 1 plane may result in curve changes in the other 2 planes. Changes of the body alignment and muscle control may also contribute to the phenomenon. Thus, data on the spinal shape changes both in the frontal and sagittal planes owing to LTS are helpful for a better understanding of the effects of LTS on the spinal curve.

The purposes of the present study were to develop a radiographic technique that can be used to measure the spinal alignment of a person in a seated position, and use it to investigate the effects of LTS on the frontal and sagittal spinal alignment in persons who had SCI with scoliosis.

\section{METHODS}

Ten men and 7 women participated voluntarily in the present study after we obtained informed consents. Table 1 lists the main demographic features of the enrolled subjects. Subjects met the following criteria: (1) SCI between C4 and T12, (2) onset over 1 year, (3) sitting on the wheelchair more than 4 hours a day, (4) diagnosed thoracic or lumbar scoliosis through anteroposterior (AP) radiographs, (5) flexible scoliosis, confirmed by supine and side-lying bending radiographs. The SCI was neurologically complete, as defined by the American Spinal Injury Association. ${ }^{26}$ All subjects gave written informed consent, as approved by the Medical Ethics Committee at the National Taiwan University Hospital.

In a radiography room, the subject sat relaxed on an adjustable seating system ${ }^{\mathrm{a}}$ without any extra support except for a seat belt and foot rests (fig 1). The seat plane was level with a $90^{\circ}$ backrest. We adjusted the dimensions of the chair according to each subject's anthropometry. The seat depth and foot rest height were adjusted according to the thigh and leg lengths. These steps allowed the customization of the adjusted seating system to the specific subject. The backrest of the chair was made of transparent acrylic boards to prevent the degradation of the quality of the radiographic images. During the experiment, we instructed subjects to put their hands on their thighs for support and to sit as much upright as possible. Radiographs of the thoracic and lumbosacral spine in the AP and lateral directions were taken with a computerized radiography system. ${ }^{\mathrm{b}}$ The radiation dose was about $1 \mathrm{mSv}$ in 1 exposure. Apart from the radiographic measurements, the spinal alignment was also photographed from AP and lateral views using a digital camera. The shape of the spine was described by stickers attached to the spinous processes of the vertebrae via careful palpation. To examine the effects of LTS, 3-point lateral trunk supports made of transparent acrylic boards were then applied to the subject by an experienced occupational therapist, based on the shape of the subject's spinal curve from the radiographs. Radiographs in the AP and lateral directions were then taken in the same way as in the without-LTS condition described above. It took about 1 hour to complete the experiment.

To quantify the changes of the spinal curve with LTS in the frontal plane, we measured Cobb angles ${ }^{2,3}$ and scoliotic indi$\mathrm{ces}^{3}$ from the radiographic images in both the with- and without-LTS conditions. The Cobb method has been commonly used to measure and describe the severity of scoliosis in clinical research and practice because it is easy and quick to calculate. ${ }^{1}$ However, because only the angle of curvature defined by the ends of the scoliotic curve is obtained, the change of the whole spine is not included in the Cobb method. The scoliotic index proposed by Greenspan overcomes the limitation by considering the deviation of each involved vertebra (fig $2) .^{3}$ It is calculated as follows.

$$
\text { Scoliotic Index }=\frac{a a^{\prime}+b b^{\prime}+c c^{\prime}+\cdots+h h^{\prime}}{x y}
$$

where $a$ to $h$ represent each vertebra that was considered as an integral part of the curve; $a a^{\prime}, b b^{\prime}, \ldots, h h^{\prime}$ are the lengths of the line segments drawn from the center of each vertebral body and perpendicular to the spinal line that connects the center of the vertebrae immediately above and below the upper and lower end vertebrae of the curve; and $x y$ is the length of the spinal line (fig 2). A scoliotic index of zero denotes a straight spine. The bigger the scoliotic index the more severe the scoliosis.

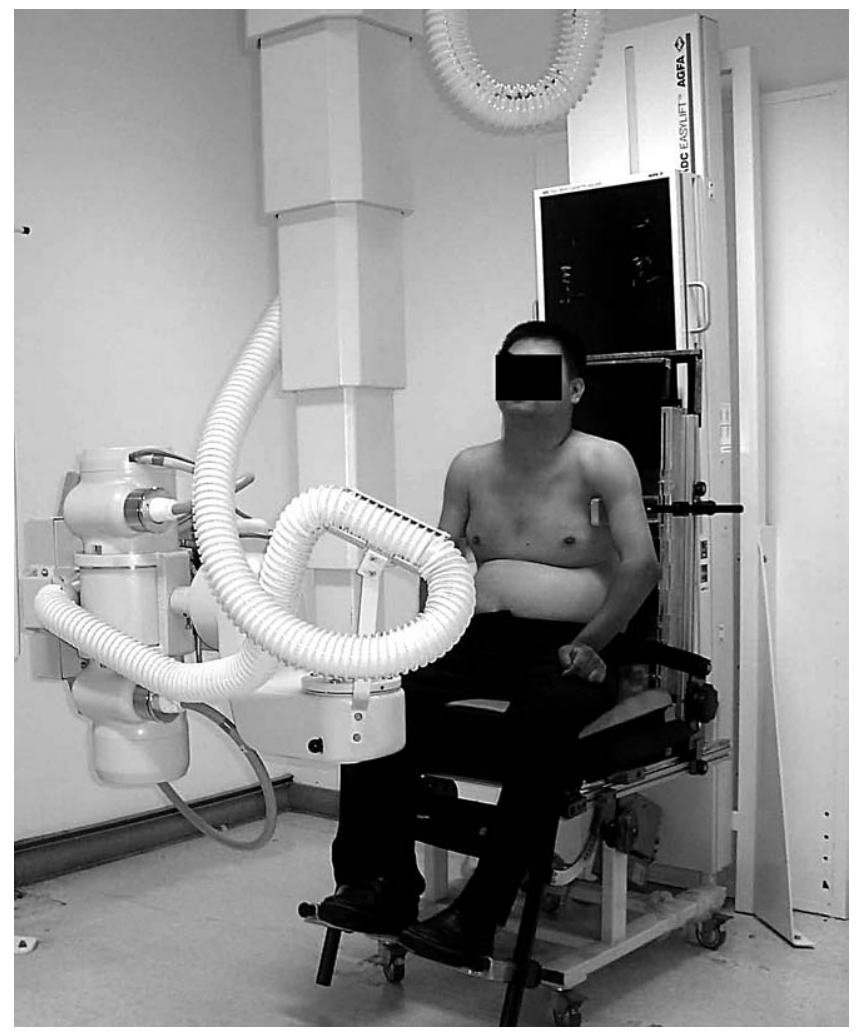

Fig 1. The experimental setup. Each subject was seated on an adjustable seating system in place for radiographic imaging. 


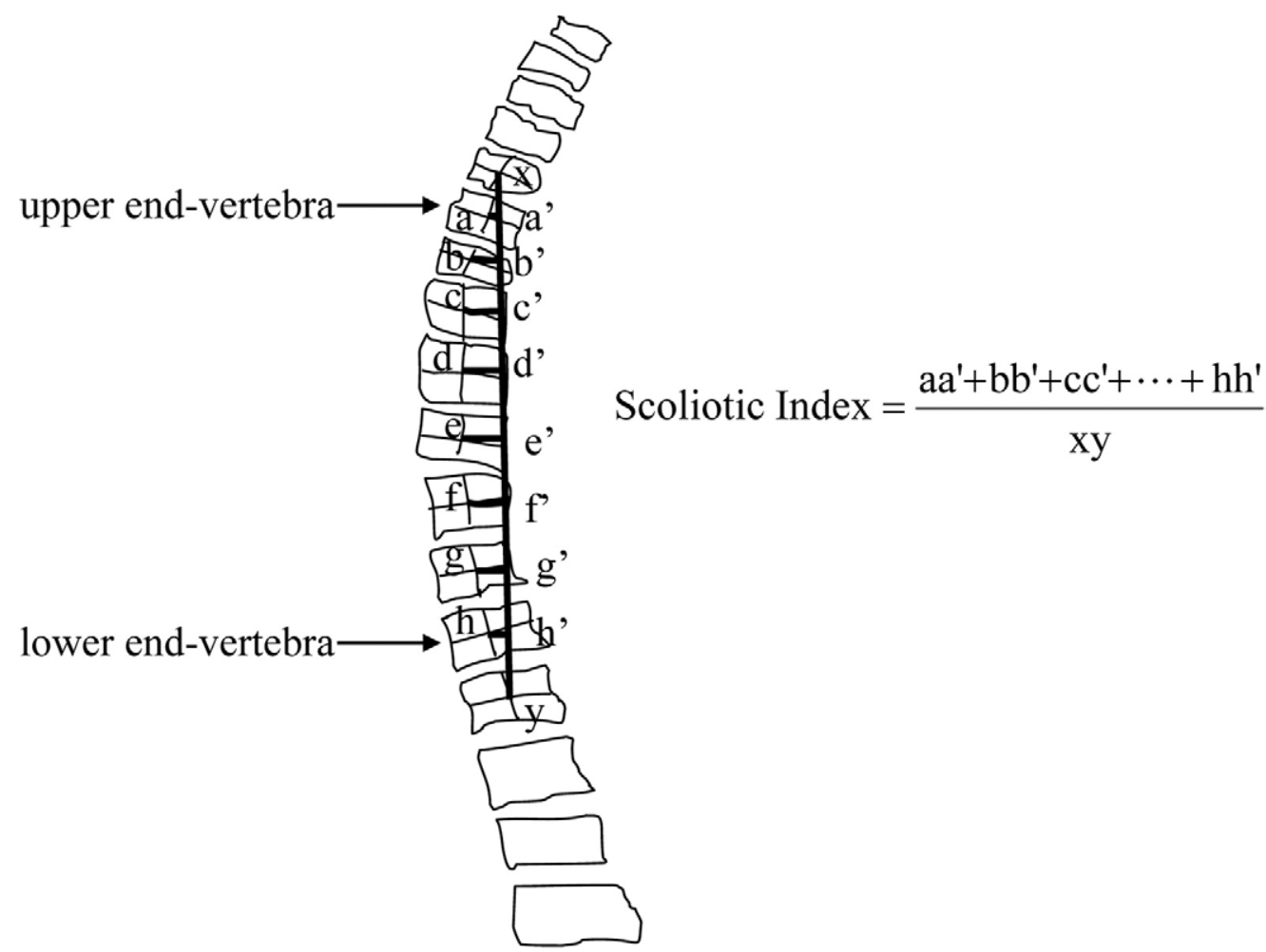

Fig 2. Scoliotic index for measuring scoliosis severity.

In the sagittal plane, we measured the thoracic angle on the lateral radiograph between the upper endplate of the T6 vertebra and the lower endplate of the T12 vertebra using the Cobb method, while the lumbar angle was measured from the upper endplate of the L1 vertebra to the lower endplate of the L5 vertebra. ${ }^{16}$ These 2 variables, together with the Cobb angles and scoliotic indices, were all measured by an orthopedic surgeon (TMW) using a house-developed software system in Matlab, version $6.5 .^{\mathrm{c}}$ The software loaded the image and then corrected the image distortion using the lead grid before assisting the user to draw lines for the calculation of the Cobb angles and scoliotic indices.

We analyzed the measured data using a paired $t$ test with a significance level of .05 to compare the differences between the without- and with-LTS conditions. Relative change in angle (RCA) with LTS was defined as the percent change of the Cobb angle relative to the Cobb angle in the without-LTS condition. The correlation of the Cobb angles and scoliotic indices was examined with the Pearson product moment correlation. SPSS ${ }^{\mathrm{d}}$ was used for all the statistical analyses.

\section{RESULTS}

The main clinical features of all 17 subjects before and after applying LTS are listed in table 2. The AP radiographic images of a subject (C5, class A) with line segments drawn for the calculation of the Cobb angles without and with LTS are given in figure 3 . The means of the Cobb angles \pm standard error (SE) of the subjects in the frontal plane without and with LTS were $39.57^{\circ} \pm 5.24^{\circ}$ and $30.45^{\circ} \pm 4.64^{\circ}$, respectively. Seating with LTS gave significantly smaller Cobb angles than without LTS $(P<.001)$, the mean difference \pm SE being $9.12^{\circ} \pm 1.64^{\circ}$. An average RCA of $26.16 \% \pm 4.23 \%$ was noted after applying LTS. The mean scoliotic indices of the subjects without and with LTS were $.55 \pm .09$ and $.46 \pm .07$, respectively. The improvement of the spinal curve with LTS was also indicated by a significant mean reduction of $.09 \pm .04$ in the scoliotic indices $(P=.027)$. The Cobb angles and scoliotic indices for all subjects correlated highly ( $r=.783, P<.001$ ) (fig 4). There was a weak correlation between the severity of scoliosis (Cobb angles) and the corresponding RCA $(r=-.347, P=.172)$.

The mean of the lumbar angles without and with LTS were $29.50^{\circ} \pm 5.73^{\circ}$ and $24.78^{\circ} \pm 5.56^{\circ}$, respectively. The lumbar angle was significantly decreased with LTS $(P<.001)$, the mean reduction and mean $\mathrm{RCA}$ being $4.72^{\circ} \pm 0.93^{\circ}$ and $24.24 \% \pm 5.68 \%$, respectively. However, there was no significant difference in the thoracic angles between the 2 seating configurations (without LTS: $37.95^{\circ} \pm 4.03^{\circ}$; with LTS: $34.54^{\circ}$ $\pm 4.47^{\circ}$; mean difference: $3.40^{\circ} \pm 3.99^{\circ} ; P=.41$; mean RCA: $1.68 \% \pm 12.4 \%$ ), although a decreasing trend after using LTS was present. As often observed in clinical practice, a better posture alignment with LTS, including a more symmetric and erect trunk and head-neck posture in both the frontal and sagittal planes, could be seen from photographs of a subject (fig 5).

\section{DISCUSSION}

Special seating with LTS is among the methods found most acceptable by persons with SCI and clinicians for managing scoliosis after SCI. ${ }^{8,21}$ However, as indicated in the introduction, no study has quantified the influence of LTS in a special seating system on the spinal alignment in persons with SCI. One reason for this is the difficulties in measuring or assessing the spine of persons with SCI, including the inability of photographic methods to measure skeletal alignment directly, ${ }^{4,5,27}$ and technical difficulties in taking spine radiographs of persons with SCI who have lost the ability to sit independently, ${ }^{16,28}$ while they are sitting in special seating or a wheelchair. Holmes et $\mathrm{al}^{22}$ investigated the effects of lateral support pads on the correction rate for the scoliotic spinal curve in subjects with $\mathrm{CP}$ by using photography. Because only the 
Table 2: Cobb Angles, Lateral Thoracic and Lumbar Angles, and Corresponding RCA Values of All Subjects Without and With LTS

\begin{tabular}{|c|c|c|c|c|c|c|c|c|c|c|}
\hline \multirow[b]{2}{*}{$\begin{array}{c}\text { Subject } \\
\text { No. }\end{array}$} & \multirow[b]{2}{*}{$\begin{array}{l}\text { Level } \\
\text { of SCl }\end{array}$} & \multicolumn{3}{|c|}{ Cobb Angles } & \multicolumn{3}{|c|}{ Lateral Thoracic Angles } & \multicolumn{3}{|c|}{ Lateral Lumbar Angles } \\
\hline & & $\begin{array}{c}\text { Without LTS } \\
\text { (deg) }\end{array}$ & $\begin{array}{l}\text { With LTS } \\
\text { (deg) }\end{array}$ & $\begin{array}{c}\mathrm{RCA}^{*} \\
(\%)\end{array}$ & $\begin{array}{l}\text { Without LTS } \\
\text { (deg) }\end{array}$ & $\begin{array}{l}\text { With LTS } \\
\text { (deg) }\end{array}$ & $\begin{array}{c}\mathrm{RCA}^{*} \\
(\%)\end{array}$ & $\begin{array}{l}\text { Without LTS } \\
\text { (deg) }\end{array}$ & $\begin{array}{l}\text { With LTS } \\
\text { (deg) }\end{array}$ & $\begin{array}{c}\mathrm{RCA}^{*} \\
(\%)\end{array}$ \\
\hline 1 & T9 & 65.83 & 62.06 & 5.74 & 48.12 & 42.07 & 12.57 & 11.43 & 3.60 & 68.50 \\
\hline 2 & T3 & 21.59 & 12.87 & 40.38 & 19.91 & 35.26 & -77.10 & 3.40 & 2.49 & 26.69 \\
\hline 3 & $\mathrm{T7}$ & 28.63 & 21.24 & 25.83 & 30.36 & 36.16 & -19.10 & 13.71 & 8.72 & 36.41 \\
\hline 4 & T5 & 52.95 & 30.75 & 41.93 & 50.86 & 52.82 & -3.85 & 53.05 & 51.49 & 2.93 \\
\hline 5 & T3 & 54.13 & 39.76 & 26.55 & 42.43 & 31.31 & 26.21 & 33.96 & 22.09 & 34.95 \\
\hline 6 & T9 & 18.12 & 7.59 & 58.13 & 48.88 & 70.69 & -44.62 & 72.30 & 66.82 & 7.58 \\
\hline 7 & $\mathrm{C} 6$ & 20.99 & 14.36 & 31.59 & 55.23 & 35.58 & 35.58 & 35.13 & 33.03 & 5.99 \\
\hline 8 & $\mathrm{~T} 10$ & 14.37 & 5.48 & 61.90 & 21.10 & 17.58 & 16.68 & 26.42 & 16.32 & 38.21 \\
\hline 9 & T9 & 63.52 & 57.35 & 9.72 & 14.87 & 1.47 & 90.11 & 72.35 & 62.43 & 13.71 \\
\hline 10 & T11 & 83.77 & 59.14 & 29.40 & 30.09 & 39.91 & -32.64 & 34.92 & 26.36 & 24.51 \\
\hline 11 & $\mathrm{C} 5$ & 40.94 & 25.90 & 36.73 & 47.68 & 55.85 & -17.14 & 14.56 & 15.82 & -8.65 \\
\hline 12 & T5 & 17.88 & 14.85 & 16.96 & 34.99 & 31.80 & 9.12 & 11.65 & 6.32 & 45.78 \\
\hline 13 & T5 & 51.72 & 43.74 & 15.43 & 72.71 & 30.96 & 57.42 & 66.16 & 64.77 & 2.11 \\
\hline 14 & T7 & 50.42 & 49.20 & 2.41 & 5.46 & 11.13 & -103.85 & 19.26 & 15.80 & 17.99 \\
\hline 15 & $\mathrm{C} 6$ & 15.39 & 13.18 & 14.41 & 38.22 & 31.13 & 18.55 & 26.16 & 21.08 & 19.42 \\
\hline 16 & $\mathrm{C} 5$ & 53.90 & 43.03 & 20.16 & 37.40 & 6.68 & 82.14 & 3.91 & 0.99 & 74.80 \\
\hline 17 & $\mathrm{C} 6$ & 18.58 & 17.20 & 7.45 & 46.83 & 56.90 & $\sim 21.50$ & 3.16 & 3.12 & 1.27 \\
\hline \multirow{2}{*}{\multicolumn{2}{|c|}{$\begin{array}{l}\text { Mean } \pm \text { SE } \\
\text { Mean difference } \pm \mathrm{SE}\end{array}$}} & $39.57 \pm 5.24$ & $30.45 \pm 4.64$ & $26.16 \pm 4.23$ & $37.95 \pm 4.03$ & $34.54 \pm 4.47$ & $1.68 \pm 12.40$ & $29.50 \pm 5.73$ & $24.78 \pm 5.56$ & $24.24 \pm 5.68$ \\
\hline & & \multicolumn{2}{|c|}{$9.12 \pm 1.64^{\dagger}$} & & \multicolumn{2}{|c|}{$3.40 \pm 3.99$} & & \multicolumn{2}{|c|}{$4.72 \pm .93^{\dagger}$} & \\
\hline
\end{tabular}

* Relative change in angle $(\%)=$ (without LTS angle - with LTS angle)/without LTS angle $\times 100 \%$.

${ }^{+} P<.05$ (significant difference between angles without and with LTS). 

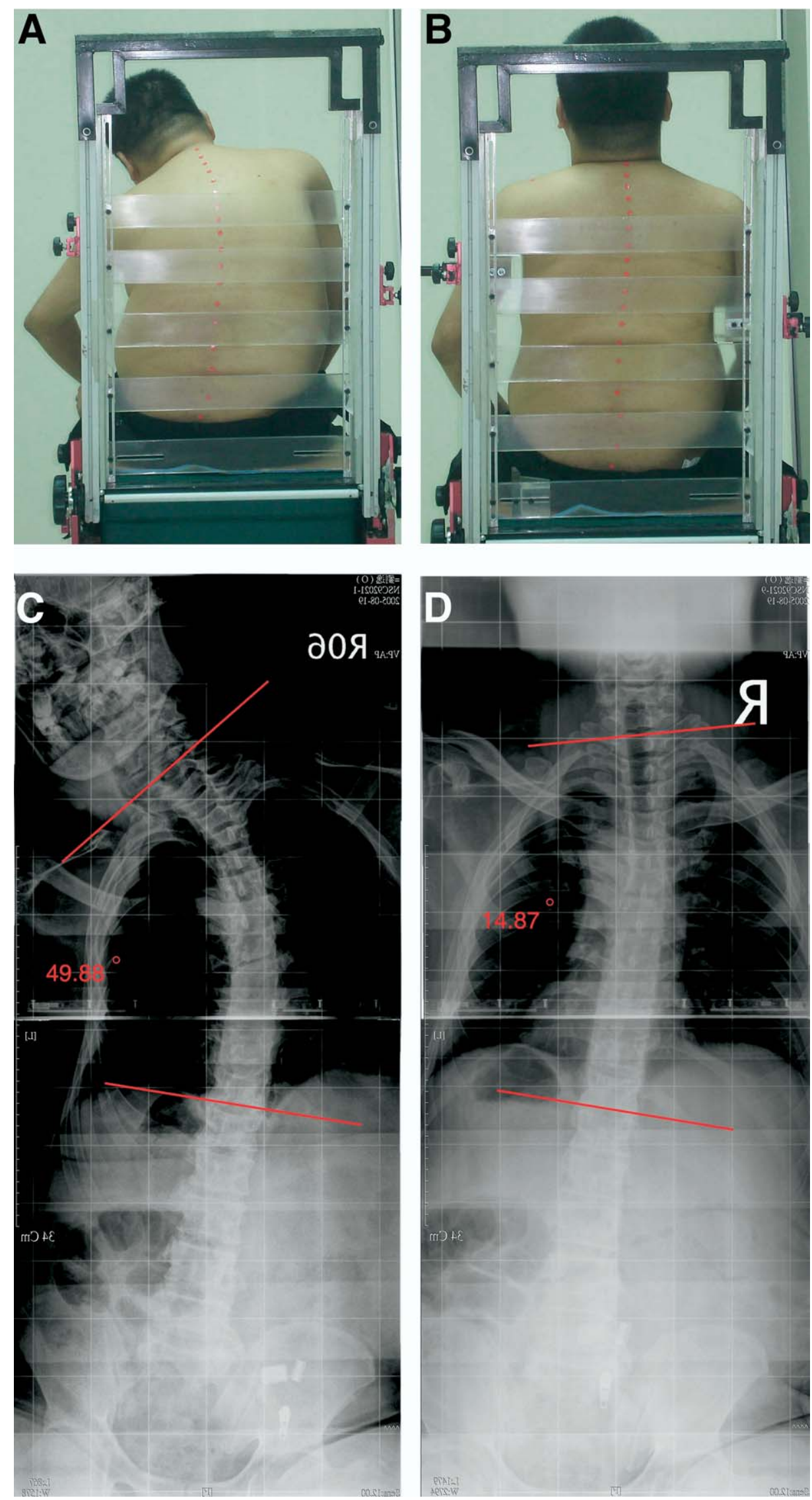

Fig 3. Posterior photographs of a subject with a complete C5 lesion (A) without and (B) with LTS. (C) and (D) are the corresponding mirror-imaged AP radiographs on which lines are drawn for the calculation of the Cobb angles. 


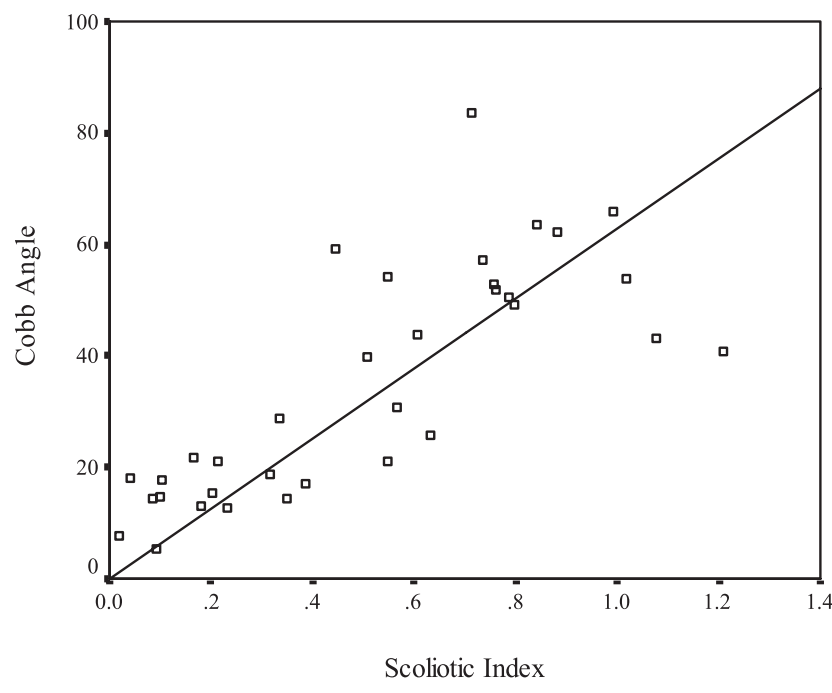

Fig 4. Correlation of Cobb angles and scoliotic indices (Pearson $r=.783, P<.001)$.

spinous processes could be palpated and identified when using photography, they had to use the spinous process angle to represent the severity of the scoliosis. This may lead to errors in the measurements because as the degree of rotation increases, the spinous process migrates toward the convexity of the curve. ${ }^{3,29}$ Most radiographs of the spine were taken in standing or supine positions, ${ }^{3}$ and few were taken in a sitting position. ${ }^{30}$ The experimental method developed in this study overcame these difficulties, thus enabling the first documentation of the effect of special seating with LTS on the changes of the frontal and sagittal scoliotic spinal alignment in persons with SCI.

The LTS in the special seating significantly improved the spinal alignment of the SCI persons with SCI in the frontal plane with reduced Cobb angles and scoliotic indices. Because the subjects had flexible scoliotic spines, the spinal curvature at the apex would be expected to increase owing to gravitational action, especially when the line of action of the gravitational force is further away from the center of the base of the spinal curve. Persistent bending as a result of this eccentric loading may accelerate the progression of the scoliosis. ${ }^{14,25}$ LTS according to the 3-point force configuration aims to provide a moment that counterbalances the bending effect of the eccentric gravitational loading on the scoliotic spine, reducing the tension on the convex side and the compression on the concave side of the apex of the spinal curve. A similar biomechanic principle was also used in orthotic devices for the nonoperative treatment of idiopathic scoliosis. ${ }^{23}$ It is noted that the RCA in the frontal plane was not associated with the severity of scoliosis, because there existed only a weak correlation between the RCA and initial Cobb angle. This suggests that LTS in special seating is effective in improving spinal alignment in the frontal plane, regardless of the severity of the scoliosis. Apart from this immediate effect, the application of LTS to support the trunk and to counterbalance the gravitational bending moment may have a long-term effect on the progression of scoliosis. The radiographic technique would need to be applied longitudinally to a population of persons with SCI who had been treated with special seating interventions to explore the long-term effect of LTS on the progression of scoliosis.

LTS not only significantly improved the spinal alignment, but also reduced the lumbar angle in the sagittal plane, resulting in a more erect seating posture. This phenomenon has not been described in the literature before. A possible explanation is that LTS provides a derotational effect on the spinal column while applying a bending moment on the spine in the frontal plane. ${ }^{24}$ This is because a scoliotic spine is often coupled with rotational deformities in the other 2 planes, the amount of which depends on the constraints from both the bony and ligamentous structures. Axial rotational deformity can also cause the spine to appear deformed in the sagittal plane. A bending moment in the body's frontal plane may also produce moment components in the spinal transverse and sagittal planes at the same time, which may help reduce the lumbar angle in the subject by improving the bony alignment and removing abnormal tension in the surrounding ligamentous structures. $^{25}$ This effect was also found for thoracic curves, but with less statistical significance, possibly because the restraint from the rib cage that was further restricted by the specialized back support limited the derotational effects. ${ }^{31}$ Without LTS a subject's trunk tended to deviate from the vertical because of the spinal deformity and loss of muscle control (see figs 3, 5). A compensatory movement of the head and neck to position the head close to an upright and center posture was noted. This is clearly shown by the photographic data. LTS helped maintain the upright and center position of the head by correcting and supporting the vertical alignment of the trunk, thus reducing the required effort for the head and neck muscles. It seems that LTS not only helped in improving the spinal alignment, but also enhanced the alignment of the head and trunk with less muscular effort.

The radiographic method combined with the adjustable seating system developed in the present study allows the AP and lateral radiographs of the thoracic and lumbosacral spine to be taken in a seated position. This technique can be very useful in monitoring changes of spinal alignment in patients who have to remain in a seated position in daily living, which cannot be achieved by traditional approaches such as photographs $s^{4,5,27}$ or radiographs taken in standing or supine positions. ${ }^{3}$ The method was used to demonstrate the immediate effects of LTS on the improvement of the spinal alignment in the frontal plane and reduction of the lumbar angles that could be obtained with a special seating system with LTS. However, because scoliosis is a complex deformity in 3 dimensions involving both bending and rotation of the vertebrae, ${ }^{25,32}$ often together with rib deformation, ${ }^{31}$ further development of the present method to obtain transverse plane data from the bi-planar radiographs such as using model-based 2- and 3-dimensional registration techniques $^{33}$ is needed. Apart from LTS, further research effort will be needed for the quantification of the long-term effects of other components of special seating, such as pelvic support, on the alignment of the spine.

\section{CONCLUSIONS}

A radiographic method combined with an adjustable seating system was developed which can be used to measure the frontal and sagittal spinal alignment of a person in a seated position. The method was used to quantify the immediate effects of special seating with LTS on the changes of the frontal and sagittal spinal alignment in persons with SCI. The results showed that LTS significantly improved the spinal alignment in the frontal plane, regardless of the severity of scoliosis. LTS also reduced the lumbar angle in the sagittal plane, resulting in a more erect seating posture. Because scoliosis is a complex deformity in 3 dimensions, further investigation using a 3-dimensional measurement technique is necessary to provide additional data in the transverse plane. The quantification of the long-term effects of LTS as well as other components of special seating also requires further study. 

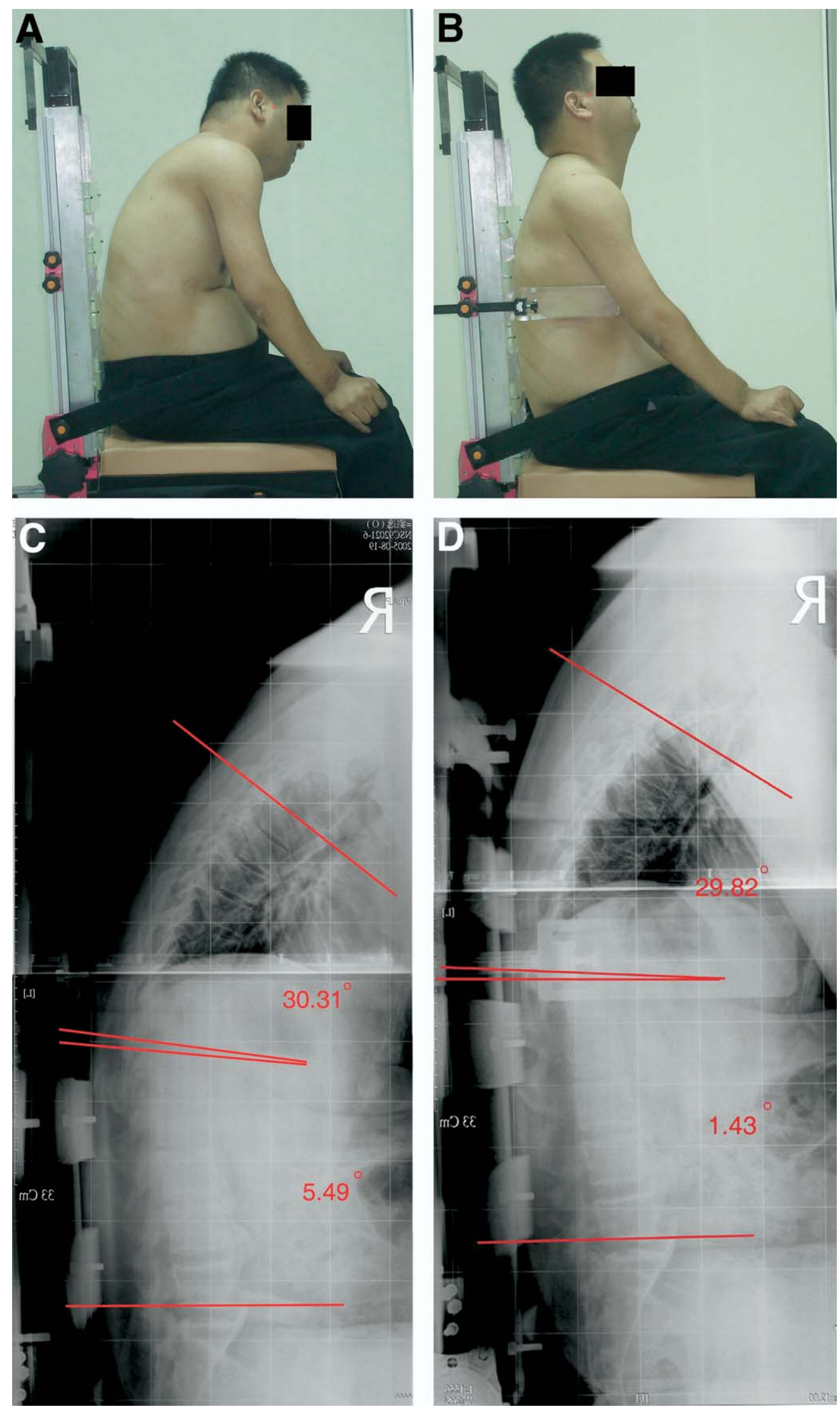

Fig 5. Lateral photographs of a subject with a complete C5 lesion (A) without and (B) with LTS. (C) and (D) are the corresponding radiographs. 


\section{References}

1. Keim HA. Scoliosis. Clin Symp 1978;30:1-30.

2. Magee DJ. Assessment of posture. In: Magee DJ, editor. Orthopedic physical assessment. 4th ed. Philadelphia: WB Saunders; 2002. p 873-903.

3. Greenspan A. Scoliosis and anomalies with general affect on the skeleton. In: Greenspan A, editor. Orthopedic imaging: a practical approach. 4th ed. Philadelphia: Lippincott Williams \& Wilkins; 2004. p 927-63.

4. Alm M, Gutierrez E, Hultling C, Saraste H. Clinical evaluation of seating in persons with complete thoracic spinal cord injury. Spinal Cord 2003;41:563-71.

5. Bolin I, Bodin P, Kreuter M. Sitting position-posture and performance in C5-C6 tetraplegia. Spinal Cord 2000;38:425-34.

6. Hobson DA. Comparative effects of posture on pressure and shear at the body-seat interface. J Rehabil Res Dev 1992;29:21-31.

7. Minkel JL. Seating and mobility considerations for people with spinal cord injury. Phys Ther 2000;80:701-9.

8. Salerno S, Kirshblum S. Wheelchairs/adaptive mobility equipment and seating. In: Kirshblum S, Campagnolo DI, DeLisa JA, editors. Spinal cord medicine. Philadelphia: Lippincott Williams \& Wilkins; 2002. p 578-99.

9. Samuelsson K, Larsson H, Thyberg M, Tropp H. Back pain and spinal deformity - common among wheelchair users with spinal cord injuries. Scand J Occup Ther 1996;3:28-32.

10. Hsu JD. The natural history of spine curvature progression in the nonambulatory Duchenne muscular dystrophy patient. Spine 1983;8:771-5.

11. Turner JA, Cardenas DD, Warms CA, McClellan CB. Chronic pain associated with spinal cord injuries: a community survey. Arch Phys Med Rehabil 2001;82:501-9.

12. Lancourt JE, Dickson JH, Carter RE. Paralytic spinal deformity following traumatic spinal-cord injury in children and adolescents. J Bone Joint Surg Am 1981;63:47-53.

13. Saito N, Ebara S, Ohotsuka K, Kumeta H, Takaoka K. Natural history of scoliosis in spastic cerebral palsy. Lancet 1998;351: 1687-92.

14. Wilkins KE, Gibson DA. The patterns of spinal deformity in Duchenne muscular dystrophy. J Bone Joint Surg Am 1976;58: 24-32.

15. Lonstein JE, Akbarnia A. Operative treatment of spinal deformities in patients with cerebral palsy or mental retardation. An analysis of one hundred and seven cases. J Bone Joint Surg Am 1983;65:43-55.

16. Mac-Thiong JM, Labelle H, Poitras B, Rivard CH, Joncas J. The effect of intraoperative traction during posterior spinal instrumentation and fusion for adolescent idiopathic scoliosis. Spine 2004; 29:1549-54.

17. Kim HS, Park JO, Lee HM, et al. Radiographic and functional outcome after surgical management of severe scoliosis in skeletally immature patients with muscular dystrophy. J Spinal Disord Tech 2004; 17:505-10.

18. Goldberg CJ, Moore DP, Fogarty EE, Dowling FE. Adolescent idiopathic scoliosis: the effect of brace treatment on the incidence of surgery. Spine 2001;26:42-7.

19. Rowe DE, Bernstein SM, Riddick MF, Adler F, Emans JB, Gardner-Bonneau D. A meta-analysis of the efficacy of non- operative treatments for idiopathic scoliosis. J Bone Joint Surg Am 1997;79:664-74.

20. Ugwonali OF, Lomas G, Choe JC, et al. Effect of bracing on the quality of life of adolescents with idiopathic scoliosis. Spine J 2004;4:254-60.

21. Cook AM, Hussey SM. Seating systems as extrinsic enablers for assistive technologies. In: Cook AM, Hussey SM, editors. Assistive technologies: principles and practice. 2nd ed. St. Louis: Mosby; 2002. p 165-211.

22. Holmes KJ, Michael SM, Thorpe SL, Solomonidis SE. Management of scoliosis with special seating for the non-ambulant spastic cerebral palsy population-a biomechanical study. Clin Biomech (Bristol, Avon) 2003;18:480-7.

23. Veldhuizen AG, Cheung J, Bulthuis GJ, Nijenbanning G. A new orthotic device in the non-operative treatment of idiopathic scoliosis. Med Eng Phys 2002:24:209-18.

24. Carpineta L, Labelle H. Evidence of three-dimensional variability in scoliotic curves. Clin Orthop Relat Res 2003;Jul(412):139-48.

25. Suzuki S, Kasahara Y, Yamamoto S, Seto Y, Furukawa K, Nishino Y. Three-dimensional spinal deformity in scoliosis associated with cerebral palsy and with progressive muscular dystrophy. Spine 1993;18:2290-4.

26. Maynard FM Jr, Bracken MB, Creasey G, et al. International Standards for Neurological and Functional Classification of Spinal Cord Injury. American Spinal Injury Association. Spinal Cord 1997;35:266-74.

27. Hastings JD, Fanucchi ER, Burns SP. Wheelchair configuration and postural alignment in persons with spinal cord injury. Arch Phys Med Rehabil 2003;84:528-34.

28. Steib JP, Dumas R, Mitton D, Skalli W. Surgical correction of scoliosis by in situ contouring: a detorsion analysis. Spine 2004; 29:193-9.

29. Herzenberg JE, Waanders NA, Closkey RF, Schultz AB, Hensinger RN. Cobb angle versus spinous process angle in adolescent idiopathic scoliosis. The relationship of the anterior and posterior deformities. Spine 1990;15:874-9.

30. Hobson DA, Tooms RE. Seated lumbar/pelvic alignment. A comparison between spinal cord-injured and noninjured groups. Spine 1992;17:293-8

31. Aubin CE, Dansereau J, de Guise JA, Labelle H. Rib cage-spine coupling patterns involved in brace treatment of adolescent idiopathic scoliosis. Spine 1997;22:629-35.

32. Stokes IA, Gardner-Morse M. Analysis of the interaction between vertebral lateral deviation and axial rotation in scoliosis. J Biomech 1991;24:753-9.

33. DeFrate LE, Sun H, Gill TJ, Rubash HE, Li G. In vivo tibiofemoral contact analysis using 3D MRI-based knee models. J Biomech 2004;37:1499-504.

\section{Suppliers}

a. Aerospace Industrial Development Corp, No. 111-15, Lane 68 , Fu-Hsing N Rd, Taichung, Taiwan 407, ROC.

b. Agfa-Gevaert NV, Septestraat 27, B-2640 Mortsel, Belgium.

c. The MathWorks Inc, 3 Apple Hill Dr, Natick, MA 01760-2098.

d. Version 11.0.1; SPSS Inc, 233 S Wacker Dr, 11th Fl, Chicago, IL 60606. 